\title{
Bio-control efficiency of Bacillus thuringiensis (Berliner) against the citrus leaf miner, Phyllocnistis citrella Stainton (Lep., Gracillariidae) under laboratory conditions
}

\author{
K. Saeidi, ${ }^{1}$ E. Saeidi ${ }^{2}$ \\ ${ }^{1}$ Department of Plant Protection, Agricultural and Natural Resources Research and Education \\ Center, Kohgiluyeh va Boyerahmad, Province, Yasouj; ${ }^{2}$ Department of Veterinary, Kazerun Branch, \\ Islamic Azad University, Kazerun, Iran
}

\begin{abstract}
The citrus leaf miner, Phyllocnistis citrella Stainton (Lep., Gracillariidae), is one of the most destructive pest of citrus and related Rutaceae and ornamental plants in Iran. Larvae damage leaves by creating serpentine feeding mines, which have been lead to reduce yield. Resistance and toxicity problems derived from synthetic insecticides have made it necessary to find more effective and healthier alternatives; therefore, bio-insecticides (i.e., Bacillus thuringiensis) are becoming an important component in plant protection. The aim of the present study was to evaluate the efficiency of $B$. thuringiensis against $P$. citrella. Eight $B$. thuringiensis concentrations were used against $P$. citrella L3 on orange and mortality was recorded at 1, 4, 7 and 10 days after spraying. The results showed that $B$. thuringiensis significantly affected mortality of $P$. citrella. After 1, 4, 7 and 10 days of spraying $10^{8}$ concentration of $B$. thuringiensis had significantly caused the highest mortality to the pest with $59.8,68.4,73.6$ and $77.0 \%$, respectively. Then the mortality percent decreased until it reached $6.5,9.5,39.3$ and $46.7 \%$ at $10^{1}$ concentration, respectively. In conclusion, the study indicated that $B$. thuringiensis is effective in controlling $P$. citrella under laboratory conditions.
\end{abstract}

Correspondence: Karim Saeidi, Department of Plant Protection, Agricultural and Natural Resources Research and Education Center, Kohgiluyeh va Boyerahmad Province, P.0. Box 351, Yasouj, Iran.

Tel.: +98.741.3334821/+98.741.3334821 - Fax: +98.741.3334011.

E-mail: saeidi391@yahoo.com

Key words: Phyllocnistis citrella; Bacillus thuringiensis; citrus leaf miner; control; insecticidal bacterium.

Received for publication: 29 June 2015.

Revision received: 12 July 2016.

Accepted for publication: 14 July 2016.

(C) Copyright K. Saeidi, E. Saeidi, 2016

Licensee PAGEPress, Italy

Journal of Entomological and Acarological Research 2016; $48: 5403$

doi:10.4081/jear.2016.5403

This article is distributed under the terms of the Creative Commons Attribution Noncommercial License (by-nc 4.0) which permits any noncommercial use, distribution, and reproduction in any medium, provided the original author(s) and source are credited.

\section{Introduction}

Citrus is one of the important fruit crops that are useful for human being as a source of nutrition and health product. It provides high levels of vitamin $\mathrm{C}$ and potassium and some of the daily requirements for essential nutrients such as folic acid and thiamine. Citrus growing in Iran has a very old history, which goes back as far as $330 \mathrm{BC}$ (Ebrahimi, 2010). In 2013, Iran produced a total of four million tons of citrus from planted areas of about two hundred and ninthly thousand hectares with an average of 19,000 kg/ha (Agricultural Statistics, 2010).

Like many other agriculture crops, citrus production is hampered by problems, mainly of pests and diseases (French et al., 1997). One of the main insect pests that attack citrus is the citrus leaf miner, Phyllocnistis citrella Stainton (Lep., Gracillariidae), which adversely affect plant health and fruit development and enhance the development of canker disease (Heppner, 1995; Das et al., 1998; Gill, 1999; Liu et al., 1999; Mafi \& Ohbayashi, 2000; Michaud \& Grant, 2003; Beattie \& Hardy, 2004; Kahrarian, 2010).

The first record of citrus leaf miner from southern and northern Iran, with a dramatic increase and widespread dispersal, was noted in 1961 and 1994, respectively (Amiri Besheli, 2006a). The pest has five to nine generations/year, with peak periods in early summer and early autumn (Amiri Besheli, 2006b). P. citrella population increased over the years due to increasing cultivation of citrus and inappropriate agricultural practices applied by gardeners (Margobandhu, 1993; Jacas \& Pena, 2002; Moreira et al., 2006).

The control of this pest is based on chemical products. However, $P$. citrella has developed resistance to almost all pesticides used including organophosphates, pyrethroids, and carbamates, requiring higher doses or a mixture of several products for their effective control. These practices result in increased production costs and contamination of the environment (Beattie et al., 1995). Vigorous application of chemical insecticides has been used to repress $P$. citrella in the Middle East (Jafari, 1995; Jafarzadeh, 2000; Javan Moghadam, 2001). In Iran, Seraj (2001) reported that abamectin and imidacloprid caused mortality higher than 70\% to the pest under laboratory conditions (Seraj, 2001). In addition, Demir et al. (2012) in Turkey and Jafari (1997) in Iran, reported that diflubenzeron proved to be effective against $P$. citrella.

However, the use of synthetic pesticides is neither economic nor tolerable and has an undesirable effect on the environment due to their slow biodegradation in the environment, natural enemies and farmers (Jafarzadeh, 2000; Seraj, 2001). The intensive pest control programs using modern insecticides practiced in the Pakistan and Iran is not only a costly form of pest control, but also leads to resurgence of secondary pests such as mites and scale insects (Jafari, 1996). The 
adverse effects of synthetic pesticides have amplified the need for effective and biodegradable pesticides.

An alternative is the use of biological control such as the use of predators, parasitoids, and entomopathogens, including fungi, bacteria, viruses, and nematodes. Within the bacterial group, the microorganism most widely used worldwide with the highest success in the control of several insect pests is the bacterium, Bacillus thuringiensis Berliner (Bacillales: Bacillaceae). B. thuringiensis has been shown to be useful for the control of different insect pests that affect plant crops, forest trees, or those are vectors of human diseases such as dengue and malaria (Dubois \& Dean, 1950; Mahapatro \&, Gupta, 2000).

$B$. thuringiensis is a gram-positive and soil-dwelling bacterium commonly used as a biological pesticide. $B$. thuringiensis also occurs naturally in the gut of larvae of various types of lepidopteran, dipteran and coleopteran insects (Demir et al., 2012). During sporulation, many $B$. thuringiensis strains produce crystal proteins (proteinaceous inclusions), that are toxic to the larvae of Lepidoptera and other orders of invertebrates.

Because of there is no comprehensive studies on the use of $B$. thuringiensis against citrus leaf miner in Iran, therefore, the main objective of this study were to the efficacy of $B$. thuringiensis against $P$. citrella. Results presented here may be helpful for future planning of large-scale citrus cultivation in similar environmental conditions of tropics, especially for pest management purposes.

\section{Material and methods}

In this study the stock cultures of the citrus leaf miner, P. citrella and its host plant were inevitably required for the various experiments. Therefore, mass rearing both $P$. citrella and the host plant must be conducted. In principle, there are two main activities related to mass culturing of insect and planting of the host plant, Citrus sinensis L.

\section{Planting of the host plant, Citrus sinensis}

Citrus sinensis $\mathrm{L}$, common known as orange is one of the host plants that are most preferred by the citrus leaf miner, $P$. citrella (Beattie, 2004); therefore, this plant is used to rear the citrus leaf miner. The plant can be propagated through seedling and stem cutting; however, the use of seedling is preferable to stem cutting. Germination of $C$. sinensis $\mathrm{L}$. seeds was done on plastic trays $(35 \mathrm{~cm}$ long $\times 25 \mathrm{~cm}$ wide at top; $31 \mathrm{~cm}$ long $\times 21 \mathrm{~cm}$ wide at bottom; and $10 \mathrm{~cm}$ high) filled with a mixture of mineral soil, manure and sand (1:1:1). These seeds were placed a row in planting holes spaced 5 by $5 \mathrm{~cm}$ apart. The mixture was kept damp in order to hasten seed turgidity and germination. The seeds started to germinate after 2-3 weeks. The seedlings, 10 to $15 \mathrm{~cm}$ tall, were then transplanted to plastic flower pots $(20 \mathrm{~cm}$ top diameter $\times 15$ $\mathrm{cm}$ bottom diameter $\times 18 \mathrm{~cm}$ high) containing the same mixture. Plants reaching more than $50 \mathrm{~cm}$ tall and approximately $10 \mathrm{~mm}$ in stem diameter were used to culture $P$. citrella. All plants were kept in the greenhouse agriculture research center of Yasouj, with a temperature of $33-40^{\circ} \mathrm{C}$ and relative humidity of $50-65 \%$ and natural photoperiod (Figure 1).

\section{Rearing of Phyllocnistis citrella}

The rearing of $P$. citrella was initiated from newly emerged larvae collected from citrus orchards in Gachsaran, Iran, and maintained on potted orange seedlings. The infested orange seedlings were kept in cages of $60 \times 60 \times 100 \mathrm{~cm}$ under laboratory conditions of $35 \pm 5^{\circ} \mathrm{C}$ temperature, $60 \pm 10 \%$ relative humidity and 12:12 $\mathrm{h}$ (L:D) photoperiod at the Research Laboratory of Agriculture Yasouj, Iran. The cages were covered with muslin cloth from their sides and tops to provide adequate ventilation (Figure 2). Potted orange plants were grown in an air-conditioned greenhouse in small pots.

\section{Bacillus thuringiensis}

Eight concentrations of $B$.thuringiensis var. kurstaki were selected to conduct the experiments. $B$. thuringiensis was obtained from a stock culture at the Department of Plant Protection, Faculty of Agriculture, Shiraz University. The bacteria were grown on nutrient broth to aid sporulation. The culture was then incubated on a rotary shaker (300 rpm) at $28^{\circ} \mathrm{C}$ for four days to ensure sporulation and cell lyses. Spores and crystals were harvested by centrifugation at $1.0000 \mathrm{rpm}$ for $15 \mathrm{~min}$ at $8^{\circ} \mathrm{C}$. The pellet $(3.5-4 \mathrm{~g} / \mathrm{L})$ was washed with distilled water and diluted to obtain $10^{1}-10^{8}$ viable spores/mL for use in the experiments. However, in order to prepare the different concentrations, $B$. thuringiensis pellets were diluted in sterile distilled water to get $10^{8}$ viable spores/mL and they were counted by haemocytomer slide. Hereafter, subsequent dilution to $10^{7}$ until $10^{1}$ was made from the $10^{8}$ viable spores/mL.

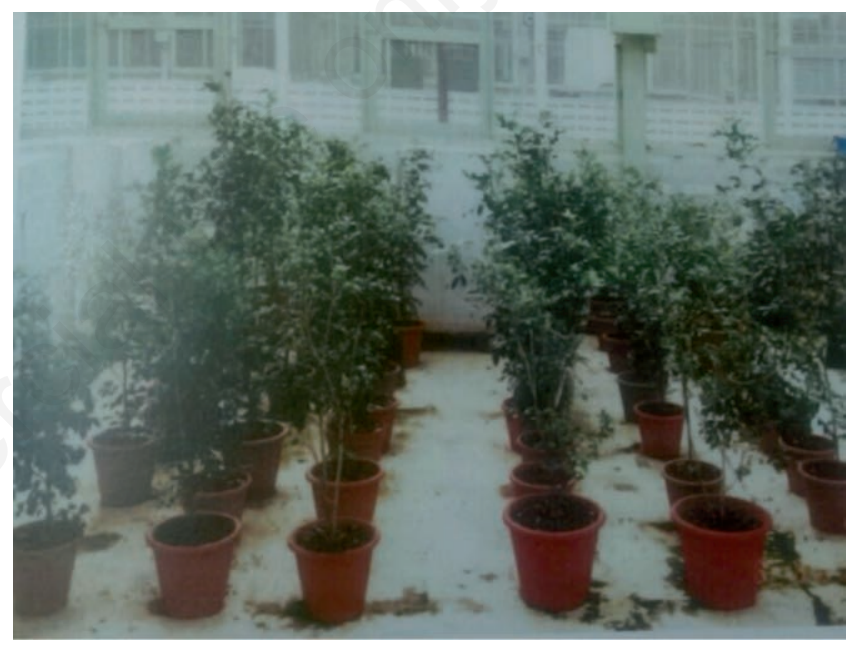

Figure 1. Citrus sinensis L., host plant for mass rearing Phyllocnistis citrella in greenhouse.

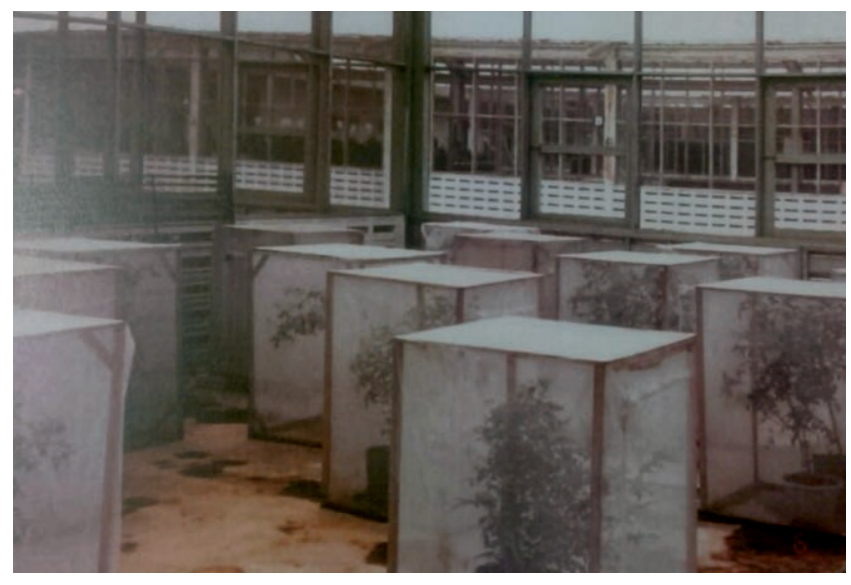

Figure 2 . The cages $(60 \mathrm{~cm}$ long $\times 60 \mathrm{~cm}$ wide $\times 100 \mathrm{~cm}$ high $)$ covered with muslin cloth that was used to rear Phyllocnistis citrella. 


\section{Treatments}

The experiments were conducted in Petri dishes, $5.5 \mathrm{~cm}$ in diameter and $1 \mathrm{~cm}$ in height, partially filled with a $0.5 \mathrm{~cm}$ thick layer of wetted cotton pad and the lid of each Petri dish had a hole closed with organdie fabric for ventilation. Citrus leaf discs of $10 \mathrm{~cm}^{2}$ area cut from uninfected citrus plants were placed in the dishes. Third larval instars of $P$. citrella were gently transferred using a Camel hairbrush into the Petri dishes in groups of ten larvae/Petri dish. Larvae in control groups $(n=10)$ were sprayed with a $1 \mathrm{ml}$ of distilled water, while larvae in treatment groups $(n=10)$ were sprayed with a $1 \mathrm{ml}$ aqueous solution of the required concentrations of $B$. thuringiensis by using a calibrated small sprayer. The Petri dishes were kept under the fore-mentioned laboratory conditions. For each concentration, three replicates were used and each Petri dish contained ten P. citrella larvae. Larval mortality was recorded at 1, 4, 7 and 10 days post spraying. Larvae were considered dead if they did not move when lightly prodded with forceps. The overall control mortality was $0.00,13.30,23.33 \%$ and $33.30 \%$ at $1,4,7$ and 10 days of the experiments.

\section{Statistical analysis}

The statistical analysis was performed using MSTAT-C statistical software and the means were compared with Duncans multiple range test (DMRT). The mortality resulting from $B$. thuringiensis treatment was adjusted for the control of mortality using Abbott's formula (Aabbott, 1925).

\section{Results}

The results showed that direct spraying of $P$. citrella larvae by all $B$. thuringiensis concentrations tested exhibited a range of mortality after 1, 4, 7 and 10 days after spraying (Figure 3). P.citrella larvae mortality was significantly affected by B.thuringiensis concentration and time after bacterial application. One day after spraying $10^{8}$ and $10^{7}$ concentrations had significantly caused the highest mortality to the larvae with $59.8 \%$ and $54.5 \%$, respectively. Then, the mortality percent decreased significantly until it reached $6.5 \%$ at $10^{1}$ concentration ( $F=15.44 ; 7,24 \mathrm{df} ; \mathrm{P}=0.000$ ). Four days after application, the mortality varied significantly among the different concentrations $(F=10.33 ; 7,24$ df; $\mathrm{P}=0.000$ ), in which it reached $68.4 \%$ at $10^{8}$ concentration and started to decrease with decreasing $B$. thuringiensis concentrations until it reached $9.5 \%$ at $10^{1}$ concentration. Mortality levels were relatively higher at seven days than at one day and four days post spraying, in which the mortality levels reached up to $73.6 \%$ at $10^{8}$ concentration, whereas the least mortality was recorded at $10^{1}$ concentration with $39.3 \%$ ( $F=8.78 ; 7,24 \mathrm{df} ; \mathrm{P}=0.000)$. Ten days after spraying, the percentage of mortality was the highest compared with 1,4 and 7 days after application. However, there were significant differences in the mortality percent among the different concentrations of $B$. thuringiensis, where it was $77.0 \%$ at $10^{8}$ concentration, while the least mortality of $46.7 \%$ was recorded at $10^{1}$ concentration.
A)

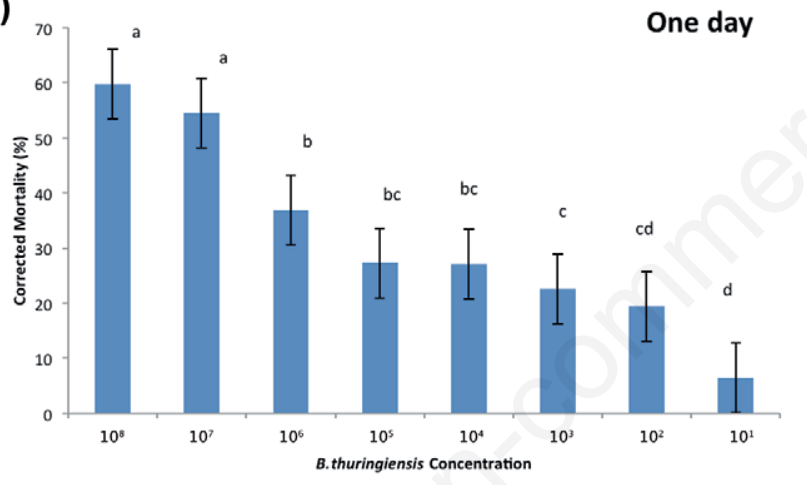

B)

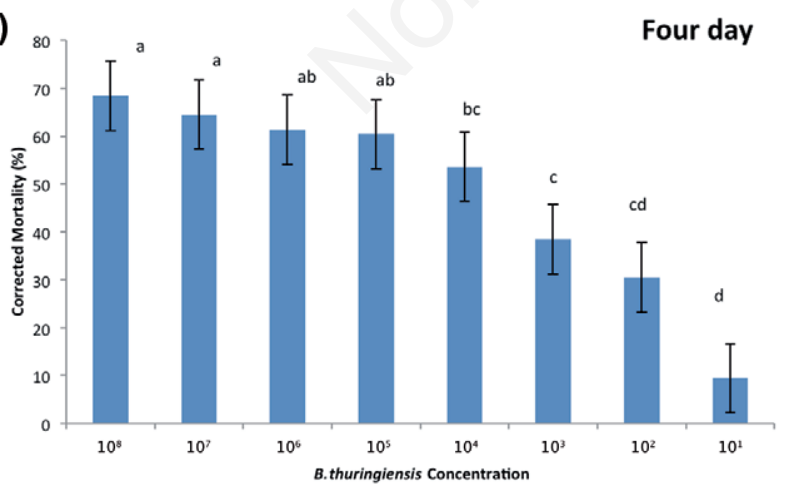

C)

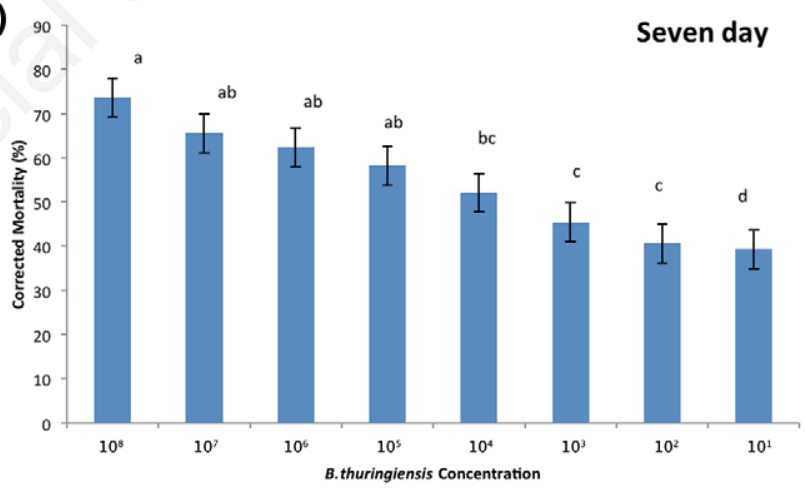

D)

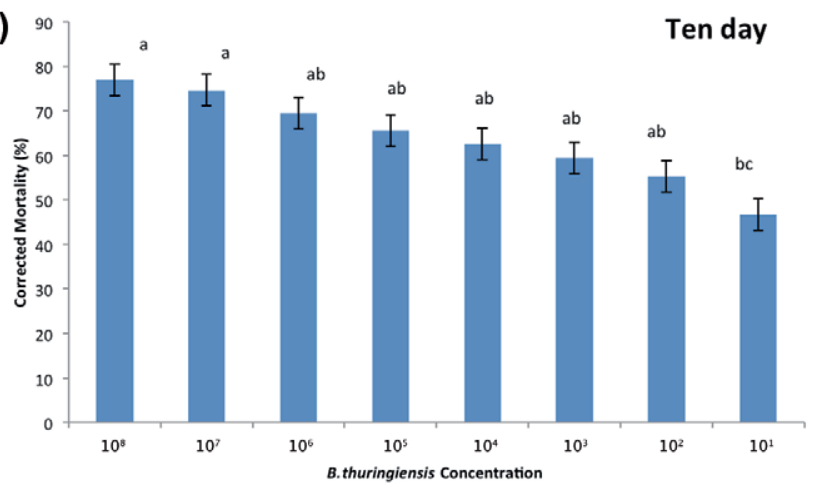

Figure 3. A) Corrected mortality percent of third larval instars of Phyllocnistis citrella after one day of spraying of Bacillus thuringiensis in direct spray test. [Different letters above bars indicate significant difference among the different $B$. thuringiensis concentrations]. B) Corrected mortality percent of third larval instars of $P$. citrella after four days of spraying of $B$. thuringiensis in direct spray test. [Different letters above bars indicate significant difference among the different $B$. thuringiensis concentrations]. C) Corrected mortality percent of third larval instars of $\boldsymbol{P}$. citrella after seven days of spraying of $\boldsymbol{B}$. thuringiensis in direct spray test. [Different letters above bars indicate significant difference among the different $B$. thuringiensis concentrations]. D) Corrected mortality percent of third larval instars of $P$. citrella after ten days of spraying of $B$. thuringiensis in direct spray test. [Different letters above bars indicate significant difference among the different $B$. thuringiensis concentrations]. 
Further statistical analysis of results among the different days within the same concentration of $B$. thuringiensis showed that there was a significant increase in mortality for all $B$. thuringiensis concentrations at higher treatment times (Figure 3 ). The percentage mortality of $P$. citrella larvae was significantly higher after 10 days post spraying followed by 7 days and then by 4 days and the least mortality was recorded at 1 day after application for all concentrations $(F=4.40 ; 24.18 ; 3,12 \mathrm{df}$; $\mathrm{P}=0.000-0.037$ ).

The overall corrected mortality percent of third larval instars of P.citrella in all days as a result of spraying with different concentrations of B. thuringiensis is shown in Figure 4A. The $10^{8}$ concentration resulted in the highest mortality with $75.6 \%$ and it was significantly higher than that caused by any of the other $B$. thuringiensis concentrations, while the lowest mortality was recorded for $10^{1}$ concentration with only $23.7 \%$ ( $F=11.45 ; 7,96 \mathrm{df} ; \mathrm{P}=0.000)$. There was also a positive correlation of 0.655 , significant $(0.000)$ at 0.01 probability level. This means that with increasing the concentration of $B$. thuringiensis up to $10^{8}$ there was an increase in the mortality of $P$. citrella.

The overall corrected mortality percent of $P$. citrella in all concentrations of $B$. thuringiensis on the different days after spraying is shown in Figure 4B. The results showed that the mortality was significantly increased with time and was $33.5 \%, 51.4 \%, 60.3 \%$ and $71.5 \%$ after 1,4 , 7 and 10 post spraying, respectively $(F=12.55 ; 3,96 \mathrm{df} ; \mathrm{P}=0.000)$. Also, there was a positive correlation of 0.567 , significant $(0.000)$ at 0.01 probability level.
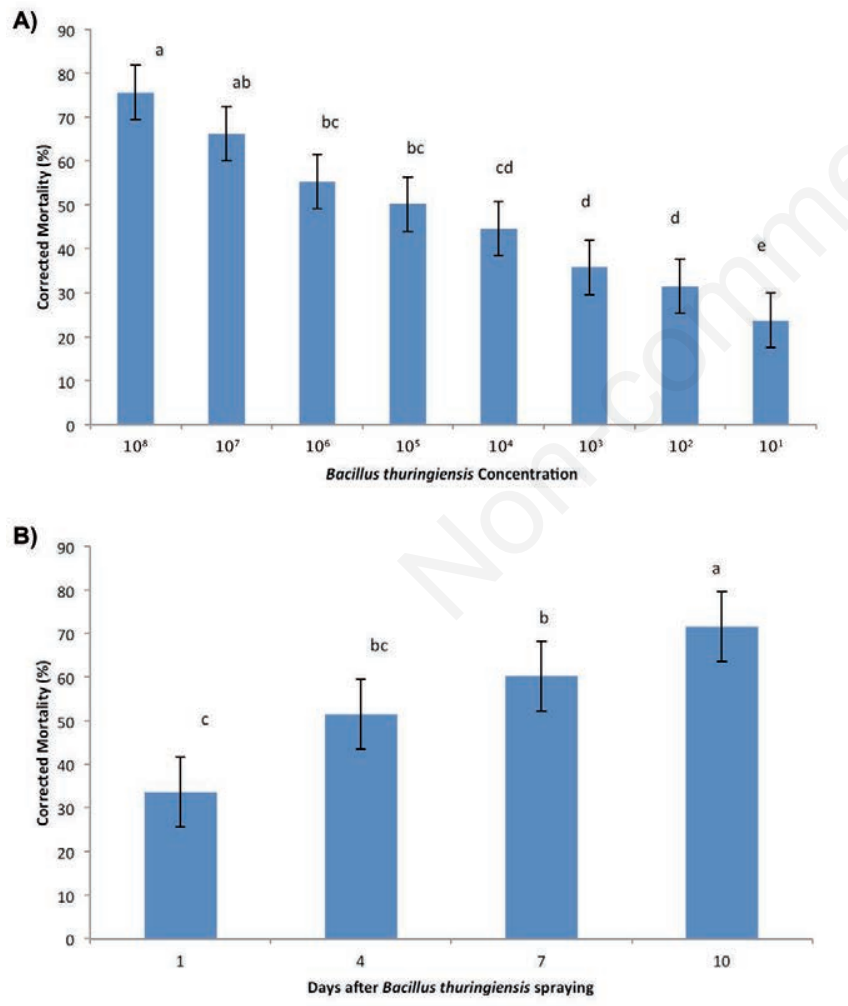

Figure 4. A) Overall corrected mortality percent of third larval instars of Phyllocnistis citrella on all days as a result of spraying with different concentrations of Bacillus thuringiensis. [Different small letters above bars indicate significant differences among the different $B$. thuringiensis concentrations]. B) All concentrations of $B$. thuringiensis on the different days after spraying. [Different small letters above bars indicate significant differences among the different days $(B)$ at $P<0.05$ (one-factor analysis of variance)].

\section{Discussion}

The indiscriminate and injudicious use of insecticides has led to a number of adverse effects in the environment. The undesirable effects of these chemical insecticides used against insect pests in crops warrants the development of strategies that could eliminate or reduce the involvement of insecticides for controlling insect pests. The citrus leaf miner, P. citrella Stainton (Lep., Gracillariidae) originated from southeast Asia and established itself as a major pest of citrus throughout the Middle East (Moreira et al., 2006), where Iran is located. The leaf miner attacks all cultivars of citrus, related species within the Rutaceae family, and several ornamentals (French et al., 1997). Plant damage is caused by leaf miner larvae as they bore through the leaf epidermis. Leaves become chlorotic, often deformed, and susceptible to infection by fungi or bacteria.

Preliminary field trials with selected insecticides indicate the superiority of Dimilin (diflubenzuron) over Diazinon, Zolone (Phosalone) and Ekamet (Etrimfos) in controlling citrus leaf miner in northern Iran, but it is not totally effective (Amiri Besheli, 2006a). But, it is well known that continuous use of chemical insecticides is neither economic nor sustainable and has a negative impact on the environment, natural enemies and gardeners. Moreover, $P$. citrella has a long history of resistance to many chemical insecticides, and development of resistance against a chemical sometimes makes it difficult to obtain sufficiently high control (Mafi \& Ohbayashi, 2000). Therefore, efforts are needed to develop integrated pest management strategies for the management of this pest through the use of bio-pesticides. Results of the present study indicated that $P$. citrella larval mortality was significantly affected by $B$. thuringiensis concentration and time after bacterial application. After 1, 4, 7 and 10 days of spraying, $10^{8}$ concentration of B.thuringiensis had significantly caused the highest mortality to the pest with 58.6, 68.4, 73.6 and 77.0\%, respectively. Comparing the results of this study with another study conducted by Amiri-Beshli (Amiri Besheli, 2006b) to control the citrus leaf miner with B.thuringiensis, mineral oil, insecticidal emulsion (garlic extract, plant detergent soap and food additive) and insecticidal gel (plant oil and plant extracts) under the laboratory conditions, insecticidal emulsion (67\%) caused higher mortality to $P$. citrella larvae than insecticidal gel (62\%), $B$. thuringiensis (49\%) and mineral oil (37\%).

The efficacy of B.thuringiensis was decreased with decreasing its concentration and was 5.3, 17.5, 19.6 and $47.0 \%$ at concentration after $1,4,7$ and 10 days after spraying respectively. This might be due to the fact that B.thuringiensis product proteinase activity was lower in its effect to $P$. citrella. These results are in agreement with results obtained by Beattie and Hardy (Beattie \& Hardy, 2004), who found that low concentration of B.thuringiensis caused low mortality to Diaprepes abbreviates (Coleoptera: Curculionidae).

\section{References}

ABBOTT W.S., 1925 - A method of computing the effectiveness of an insecticide. - J. Econ. Entomol. 18: 265-267.

AGRICULTURAL STATISTICS, 2010 - Department of Statistics, Ministry of Agriculture, Islamic Republic of Iran.

AMIRI BESHELI B., 2006a - Toxicity evaluation of Avant, Buprofezin and Pyriproxifen pesticides against Phyllocnistis citrella Stainton (Lepidoptera: Gracillariidae). - Pak. J. Biol. Sci. 9: 2483-2487.

AMIRI BESHELI B., 2006b - Efficacy of Bacillus thuringiensis, mineral oil, insecticidal emulsion and insecticidal gel against Phyllocnistis citrella Stainton (Lepidoptera: Gracillariidae). - Plant Prot. Sci. 44:68-73. 
BEATTIE A., HARDY S., 2004 - Citrus leaf miner. - Department of Primary Industries, Industry and Investment New South Wales.

BEATTIE G.A.C., LIU Z.M., WATSON D.M., CLIFT A.D., JIANG L., 1995 Evaluation of petroleum spray oils and polysaccharides for control Phyllocnistis citrella Stainton (Lepidoptera: Gracillariidae). - J. Aust. Entomol. Soc. 34: 349-353.

DAS A., ROY T.C.D., BHATTACHARYYA B., 1998 - Biology of citrus leaf miner Phllocnistis citrella Stainton. - J. Agric. Sci. Soc. North East India. 11: 51-54.

DEMIR I., ERYUZLU E., DEMIRBAG Z., 2012 - A study on the characterization and pathogenicity of bacteria from Lymantria dispar L. (Lepidoptera:Lymantriidae). - Turk. J. Biol. 36: 459-468.

DUBOIS N.R., DEAN D.H., 1950 - Synergism between Cryl A insecticides crystal proteins and spores of Bacillus thuringiensis, other bacterial spores and vegetative cells against Lymantria dispar (Lepidoptera: Lymantriidae) larvae. - Environ. Entomol. 24:17411747.

EBRAHIMI Y., 2010 - The evolutionary development of citrus growing and nursery activities in Iran. - Ramsar Citrus Experimental Station, Ramsar, Iran.

FRENCH J.V., LEGASPI J., VILLARREAL S., SALDANA R., 1997 Management of citrus leaf miner in Texas: Chemical options. Subtopic. Plant Sci. 49: 65-70.

GILL R.J., 1999 - Citrus leaf miner found in California. California Department Food and Agricultural. - California Plant Pest and Disease Report. 18: 79-80.

HEPPNER J.B., 1995 - Citrus leaf miner, Phyllocnistis citrella (Lep., Gracillariidae) on fruit in Florida. - Florida Entomol. 78: 183-186.

JACAS J.A., PENA J.E., 2002 - Calling behavior of two different population of Phyllocnistis citrella (Lepidoptera: Gracillariidae). Effects of age and photoperiod. - Florida Entomol. 85: 378-381.

JAFARI M., 1995 - Introduction of new pest in Mazandran citrus orchards with name citrus leaf miner Phyllocnistis citrella Stainton (Lepidoptera: Gracillariidae). - Twelfth Iranian Plant Protection Congress, Karaj, Iran. Page 211.

JAFARI M., 1996 - Report of the Workshop on citrus leaf miner
Phyllocnistis citrella Stainton (Lepidoptera: Gracillariidae) and its control in the Near East. - Safita (Tartous), Syria.

JAFARI M., 1997 - Effect of chemical insecticides against citrus leaf miner Phyllocnistis citrella Stainton (Lepidoptera: Gracillariidae) in nursery. Phyllocnistis citrella Stainton (Lepidoptera: Gracillariidae). Thirteenth Iranian Plant Protection Congress, Karaj, Iran. Page 119.

JAFARZADEH M., 2000 - Biology and comparison application methods Imidacloprid against of citrus leaf miner Phyllocnistis citrella Stainton (Lepidoptera: Gracillariidae). - Master thesis Gilan University. Faculty of Agriculture. 109 pp.

JAVAN MOGHADAM H., 2001 - Citrus leaf miner in Iran and in the world. - J. Agri. Sci. Zeyton. 121: 20.

KAHRARIAN M., 2010 - Investigation on the effects of Bacillus thuringiensis Var., Carbaryl and Diflubenzeron against the chickpea pod borer Heliothis viriplaca Hufn. (Lepidoptera: Noctuidae) in the field. - J. Entomol. Res. 2: 295-305.

LIU Z., BEATIE G., JIANG L., WATSON D.M., 1999 - Volumes of petroleum spray oil required for control of Phyllocnistis citrella Stainton (Lepidoptera: Gracillariidae) in mature citrus orchards. - J. Australian Entomol. Soc. 38: 141-146.

MAFI S.A., OHBAYASHI N., 2000 - Toxicity of insecticides to the citrus leaf miner, Phyllocnistis citrella and its parasitoids Chrysocharis pentheus (Hymenoptera: Eulophidae). - Appl. Entomol. Zool. 41:33-39.

MAHAPATRO G.K., GUPTA P., 2000 - Evening suitable for spraying Bt formulations. -Insect Environ. 5: 126-127.

MARGOBANDHU V., 1993 - Insect pest of oranges in the northern Circars. - Madras Agri. J. 21: 60-68.

MICHAUD J.P., GRANT A.K., 2003 - Integrated pest management compatibility of foliar insecticides for citrus: Indices derived from toxicity to beneficial insects from four orders. - J. Insect Sci. 3: 1-8.

MOREIRA J.A., MCELFRESH J.S., MILLAR J.G., 2006 - Identification, synthesis and field testing of the sex pheromone of the citrus leaf miner, Phyllocnistis citrella. - J. Chem. Ecol. 32: 169-194.

SERAJ AA., 2001 - Comparison of some citrus species as host citrus leaf miner Phyllocnistis citrella Stainton (Lepidoptera: Gracillariidae). - J. Plant Pest Dis. 67: 86-95. 